\title{
Cutaneous field cancerization: clinical, histopathological and therapeutic aspects

\author{
e terapêuticas
} \\ Campo de cancerização cutâneo: implicações clínicas, histopatológicas
}

\author{
Luís Antônio Ribeiro Torezan ${ }^{1}$
}

Cyro Festa-Neto ${ }^{2}$

DOI: http://dx.doi.org/10.1590/abd1806-4841.20132300

\begin{abstract}
The concept of "field cancerization" was first introduced by Slaughter in 1953 when studying the presence of histologically abnormal tissue surrounding oral squamous cell carcinoma. It was proposed to explain the development of multiple primary tumors and locally recurrent cancer. Organ systems in which field cancerization has been described since then are: head and neck (oral cavity, oropharynx, and larynx), lung, vulva, esophagus, cervix, breast, skin, colon, and bladder. Recent molecular studies support the carcinogenesis model in which the development of a field with genetically altered cells plays a central role. An important clinical implication is that fields often remain after the surgery for the primary tumor and may lead to new cancers, designated presently as "a second primary tumor" or "local recurrence," depending on the exact site and time interval. In conclusion, the development of an expanding pre-neoplastic field appears to be a critical step in epithelial carcinogenesis with important clinical consequences. Diagnosis and treatment of epithelial cancers should not only be focused on the tumor but also on the field from which it developed. The most important etiopathogenetic, clinical, histopathological and therapeutic aspects of field cancerization are reviewed in this article.
\end{abstract}

Keywords: Carcinoma, squamous cell; Keratosis, actinic; Photochemotherapy

Resumo: O conceito de campo de cancerização foi empregado, pela primeira vez, por Slaughter em 1953, estudando o tecido alterado peri-tumoral de carcinoma espinocelular, através da histopatologia. O conceito foi proposto para explicar o desenvolvimento de múltiplos tumores primários e recorrentes na mesma área onde já havia alterações histopatológicas. Os órgãos que apresentam campo de cancerização, até hoje descritos são: cavidade oral, orofaringe, pulmão, vulva, esôfago, cérvix uterino, pele, mama, cólon e bexiga. Os resultados obtidos a partir da biologia molecular sustentam o modelo de carcinogênese, onde um campo com células geneticamente alteradas têm papel fundamental. Uma importante implicação clínica é o fato de que campos com células mutadas geralmente permanecem após a cirurgia para a remoção de um tumor primário, podendo originar novos tumores, designados como segundo tumor primário ou recorrência local, dependendo do local exato e do intervalo entre a cirurgia e a detecção deste novo tumor. O desenvolvimento de campos com células mutadas é considerado uma etapa crítica na carcinogênese, com importante repercussão clínica. Assim, o diagnóstico e tratamento das lesões malignas epiteliais deve abordar não somente o tumor isolado mas sim, todo o campo onde se desenvolveu. Neste artigo, revisamos aspectos importantes da etiopatogenia, clínica, histopatologia e da terapêutica do campo de cancerização.

Palavras-chave: Carcinoma de células escamosas; Ceratose actínica; Fotoquimioterapia

Received on 21.11.2012.

Approved by the Advisory Board and accepted for publication on 20.12.2012

* Work performed at the Hospital das Clinics at the University of São Paulo Medical School - São Paulo (SP), Brazil

Conflict of interest: None

Financial Support: None

MD, PhD Assistant Professor at the Hospital das Clinicas at the University of São Paulo Medical School - São Paulo (SP), Brazil.

MD, PhD Chair Professor at the Hospital das Clinicas at the University of São Paulo Medical School - São Paulo (SP), Brazil.

(C)2013 by Anais Brasileiros de Dermatologia 


\section{INTRODUCTION}

The concept of field cancerization was introduced by Slaughter in 1953, through the study of multicentric oral mucosa neoplasms. ${ }^{1,2}$ Although there was not an appropriate definition by the time, this term was based on the histopathological studies of neoplasms arising from the oral mucosa. Thereby, authors observed that: 1- oral cancer was originated from multifocal areas with pre-cancerous alterations; 2- the tissue around the primary tumor area was histologically altered; 3 - the neoplasms, although multifocal, could coalesce; and 4- the persistence of contiguous abnormal tissue after the surgery could explain tumor relapse or the emergence of a new cancerous lesion in a previously treated area. Other organs may present field cancerization besides the oral mucosa: lungs, esophagus, vulva, uterine cervix, colon, breasts, bladder and skin. It is already established nowadays that, the accumulated genetic alterations in these fields form the basis for the carcinogenesis process. ${ }^{1,2}$

Recent studies emphasize the molecular bases that explain the development of cancer and genetic progression models have been proposed for several types of tumors. Today it is already known that the build up of genetic alterations forms the foundation that allows the progressive transformation of a normal cell into a cancerous cell. The number of such alterations increases with the degree of malignancy as seen in histopathological observations. ${ }^{2}$ In the skin, the field cancerization involves the cluster of alterations observed in a chronically photodamaged skin with several foci of non-melanocytic cutaneous neoplasms.

\section{ETIOPATHOGENESIS}

Field cancerization, either cutaneous or in other organs may be defined in molecular terms, in which the presence of mutated cells forms the groundwork that permits the progression of epithelial carcinogenesis with its relevant clinical consequences. Molecular analyses of the clinically "normal" tissue adjacent to the tumor, as well as of the surgical margins after the excision, have been made in order to better understand the field cancerization phenomena. ${ }^{3}$ The markers most used to analyze these tumors and their mutations are: loss of heterozygosity; chromosomal instability; detection, through DNA amplification (PCR), immunohistochemistry and in situ hybridization of mutations on gene TP-53. In this context, the approach of Brennan et al becomes important. ${ }^{3}$ These authors demonstrated, through the detection of mutant Tp-53 in real time PCR technique, that in more than half of the examined samples, head and neck spinocellular carcinoma cells (CEC) could still be identified in sur- gical margins that were considered free of tumor by histopathological examinations. In this study, when there were mutations present at the peri-tumoral areas, the rate of tumor recurrence was higher and statistically significant. However, in adjacent areas that were negative for gene tp-53 mutations, no relapses were observed. ${ }^{3}$ The genetic alteration markers, most commonly used in molecular analysis, support a probable monoclonal alteration on these mutated cells at the field cancerization. The interpretation of theses results suggests that head and neck CEC may arise in a contiguous field of pre-neoplastic cells, mainly of a common clonal origin. Monoclonality is based on the fact that multiple biopsies showed the same early markers of carcinogenesis. ${ }^{2.5}$ Braakhius et al proposed that, by definition, a field lesion is a pre-neoplastic lesion, and so it does not have invasive growth or metastatic capacity, and may or may not present histological characteristics of dysplasia. A detailed comparison between histopathological and molecular examination of theses cells shows that: - there is a high rate of inter-observer variability on the interpretation of the exams when several pathologists' results are compared, - mutated cells may seem normal on routine histopathological exam and - all cells, moderately or severely dysplastic have genetic alterations. ${ }^{1,6,7}$

During the development of cancer from several lineages of human cells, somatic mutations on gene TP-53 are the most frequent. They may occur in almost all types of cancer, in rates that vary from $38 \%$ to $50 \%$ in tumors of ovary, esophagus, colo-rectal, lung, larynx and head and neck. In other tumor cell lineages they may be present in rates of 5\% in tumor like leukemias, sarcomas, testicular cancer, malignant melanoma and uterine cervical cancer. ${ }^{8}$

The precursor lesions on theses fields originate in small cluster of cells with TP-53 mutations known as patches, defined as a large group of cells with the same genotype. ${ }^{2,6,79}$ Patches of TP-53 mutated cells were observed in normal skin and more frequently on photoexposed skin. ${ }^{6}$ Jonason et al demonstrated that patches of TP-53 were 10 times more frequent in skin that was exposed to UV radiation, compared to nonexposed skin.

Furthermore, using the polymerase chain reaction technique (PCR), the authors observed that 50\% of theses patches were mutated. These small clusters form the basis for field cancerization, according to recent studies. ${ }^{2}$ TP-53 mutated cells are considered clones from one common precursor cell (stem cell). When the stem cell acquires a mutation, all the clonal cells present in the patch will show the same alterations, thus explaining TP-53 gene mutation by immunohistochemical studies and PCR technique. 
Waridel et al observed frequent cluster of TP-53 mutated cells on normal oral mucosa biopsies, extracted from patients with head and neck cancer, particularly those with multiple primary tumors. ${ }^{10}$ Berg et al noted, through immunohistochemical techniques, that the expression of TP-53 in the skin of mice chronically irradiated with UV-B rays, was an early event and the longer the duration of the irradiation, the larger and more frequent were the patches. ${ }^{7}$ They also pointed that $70 \%$ of theses patches reacted strongly to PAb240, a monoclonal antibody, specific for mutant TP-53. On the other hand, mice that were irradiated only once, presented just a transitory elevation on the levels of protein TP-53, persisting for 72 hours after the exposure to UV-B. In these cases there was no PAb240 reaction, proving that it was a normal or "wild type" TP53 elevation.?

There are few recent studies addressing the size of a mutated cells patch. It is estimated that in the bladder and stomach epithelium it would be approximately $1 \mathrm{~cm}^{2}$. On the skin, the actual size appears to be $2 \mathrm{~mm}$, corresponding to about 200 TP-53 mutated cells. $^{2}$

The detection of field cancerization in patients with head and neck CEC surgically treated, plays an important role in monitoring other types of cancer. Patients submitted to surgical removal of tumors, which have a greater chance of developing a new tumor, should be considered candidates for genetic studies of the field in question. These studies may offer important data to identify the likely area of recurrence or new tumor development; monitor the disease process and even support, through the knowledge gathered on genetic alterations on that field, a future therapeutic plan for these pre-malignant lesions.

In summary, the clinical consequences that arise from the molecular alterations described above form the groundwork to the development of tumors in field cancerization. The large number of pre-malignant cells present in the field increases the chances of skin cancer development. It also explains the high rates of recurrences, as well as the appearance of new tumors after surgical removal in theses areas with mutated cells. Therefore, it is necessary to detect and monitor field cancerization, helping to achieve an early diagnosis of lesions that are potentially pre-neoplastic. ${ }^{2,3,6}$

The concept of field cancerization suggests that the apparently normal skin circling areas of actinic keratosis (QA), sustains the base for the clonal expansion of genetically altered neoplastic cells. ${ }^{1,2}$ QAs are present mainly in photoexposed areas and are characterized by diminutive erythemato-hyperkeratotic papules. QAs differ among themselves. Same authors attempted to create clinical parameters that might suggest a larger potential of transformation into CEC. These are clinical criteria, such as: presence of infiltration and inflammation, diameter $>1 \mathrm{~cm}$, rapid growth, bleeding, erythema and ulceration. ${ }^{11,12}$ As a routine, the diagnosis is essentially clinical, although histopathological exam is considered the best technique. However, considering how these lesions appear in general on cancerization fields, several of preclinical lesions are present in skin that is apparently normal. Therefore, it is mandatory that diagnosis and treatment be performed for the entire field and not only for the lesion itself. ${ }^{2,11,13}$ Non-invasive techniques such as optical confocal microscopy and photodiagnosis with protoporphyrin IX-emitted fluorescence are applied in order to identify pre-clinical lesions in fields. ${ }^{13}$

Field cancerization etiopathogenesis is still been studied to better elucidate how a second primary tumor occurs in the area where the previous one was excised. Some studies demonstrate that there is a common clonal origin for neoplastic and pre-neoplastic cells in the oral cavity, esophagus and bladder, even when lesions are as far apart from the main tumor as $7 \mathrm{~cm} \cdot{ }^{2,5}$ In other words, even with a considerable distance between the lesions, these tumors were apparently originated from the same mutant clone. The conclusion that the lesions are genetically related was based on the similarity of genetic alterations encountered. Some theories try to explain the common clonal origin of multiple tumors in the same field. The first one postulates that one cell or group of cells may migrate through the sub-mucosa and reach other areas. The other, states that tumor cells of organs that are hollow (such as oral cavity and bladder) may detach themselves and reach the lumen, thus engrafting in another area. Yet a third and most recent theory has gained more support, and it states that a large and genetically altered and contiguous field lies on the epithelium over which multiple genetically similar lesions develop themselves. ${ }^{2,5,6}$ Results indicate that a large proportion of multiple primary tumors, in the same anatomic area, arise from one unique pre-neoplastic field.

Thus, we have the concept that field cancerization has important clinical consequences. It is established that after a tumor is removed, there is a higher risk for another one to arise from the same area. Sometimes, the development of the new lesion might be explained by the incomplete resection of the primary tumor. However, in cases of complete removal, it is likely that a genetically altered field may be the source of the growth. ${ }^{3}$ The presence of a field in which lie genetically altered cells, appears to be an increasing risk factor for the growth of neoplasias. Clinical investigations are rendered difficult due to the fact that early detection of fields are made by molecular biolo- 
gy techniques that are hard to apply in a day-to-day hospital routine. To add to the difficulty is the fact that early lesions are generally sub clinic and hard to diagnose, even when early detection exams are used in routine. On the other hand, QA skin lesions (considered pre-malignant by some authors and CEC in situ by others) are easily diagnosed and arise, in general, in a field.

The acceptance that a genetically altered field increases the chances of tumor development provokes a paradigm between what is considered local relapse of a tumor and what is a second primary tumor. The latter consists of a new tumor, arising independently from the first one, on the same field. When a second tumor appears in the same field, the likelihood is that a third and a fourth may also appear on the same area. Therefore it is necessary to perform a special followup of these patients, with frequent and thorough consultations. Local relapse may be the result of a partially excised tumor, however it may also be considered as a consequence of a local field remains, which may cause the lesion to be confused with a second primary tumor. $^{1-3}$

The surgical implications on field cancerization are of great importance. In some organs, such as head and neck, vulva, bladder and colon, extensive tumor resections might not be feasible.

On the skin, the field includes clinical and sub clinical alterations that may be diagnosed through semiology, with the presence of QAs and other situations such as solar lentigo, disturbances of pigmentation, modifications of skin texture, wrinkles, xerosis, and solar elastosis. So, the definition of cutaneous field cancerization is: "a photoexposed, chronically damaged skin area with multiple QAs lesions besides other damages caused by UV radiation exposure". This "territory" behaves like a field of visible clinical and sub clinical lesions. . $^{1,2,12,13}$

The aforementioned means that pre-malignant lesions are apparent in areas previously damaged by the action of UV radiation and they originate from clusters spread in photoexposed areas. Few studies were published on this topic, and most of the literature address spinocellular carcinoma of the head and neck. $^{3}$

Recently, Braakhius et al proposed a biological multi-step model to initiate the process of cutaneous carcinogenesis. ${ }^{2}$ According to the proposed model, a stem cell acquires one or more genetic alterations (generally induced by ultraviolet radiation) and gives origin to the patch of cells with the same alteration. As a result of theses genetic alterations, these cells proliferate and give origin to an expansive clone. Gradually the lesion becomes a field, laterally expanding on the epidermis. With the gradual growth, new genetic alterations originate several sub-clones inside that field. So, even if those clones diverge in some moment in regard to the types of genetic alterations, they share a common clonal origin. The presence of a great number of mutated cells in a field is considered the determinant event to carcinogenesis. As a result of the clonal divergence, a sub-clone may transform into an invasive neoplasm at any time. Somatic mutations on gene TP-53 are frequent in field lesions and invasive CEC. Other genetic alterations on gene p-16, on the antiapoptotic complex Bcl-2 and on cyclin D1 gene, located on chromosome 11q13 are also important steps in this process. ${ }^{2,14}$ As the amount of mutated cells and genetic alterations on one field increases, so do the chances that a tumor will develop in it. Therefore, there are two critical steps in the carcinogenesis model: 1 - the conversion of a patch into a field in which cells are growing in disorder and 2- the carcinomatous transformation of sub-clones generating a tumor inside the field. ${ }^{2}$

It is interesting to notice that few histopathological or clinical studies define an altered skin field that carries the predisposition to the formation of new tumors or even pre-malignant lesions. Due to the fact that, in many times the clinical appearance of the skin is normal, our attention is focused only on clinically perceivable lesions. This concept must be revised, because the surface of an area of skin that is chronically exposed to UV radiation has higher chances of developing cutaneous neoplasms when compared to protected skin. ${ }^{14}$ And so, the entire field must be the object of study, not only the apparent lesions and also, specific laboratory techniques such molecular biology tests should be applied to define the alterations present on the area with a high likelihood of developing cancer.

\section{CLINICAL AND HISTOPATHOLOGICAL CON- SEQUENCES}

Skin that is chronically exposed to UV radiation presents early or late signs of aging. This process includes alterations in texture, coloration, pigmentation disturbances, superficial and deep wrinkles, erythema, telangiectasias, and QAs. ${ }^{15}$ These modifications are present in the extrinsic skin aging process or photoaging and form the clinical basis of the cutaneous field cancerization (Figure 1). QAs are, probably, the only macroscopic alterations on a field. In 2007, there was a proposal to clinic classify QAs in 3 subtypes: Grade 1 - lesions are discreetly palpable but not very visible; Grade 2- lesions are moderately thick and easily palpable and visible; Grade 3 - hyperkeratotic thick lesions. There is some controversy in the literature as for the differentiation of Grade 3 QAs and invasive CEC. ${ }^{16}$ 


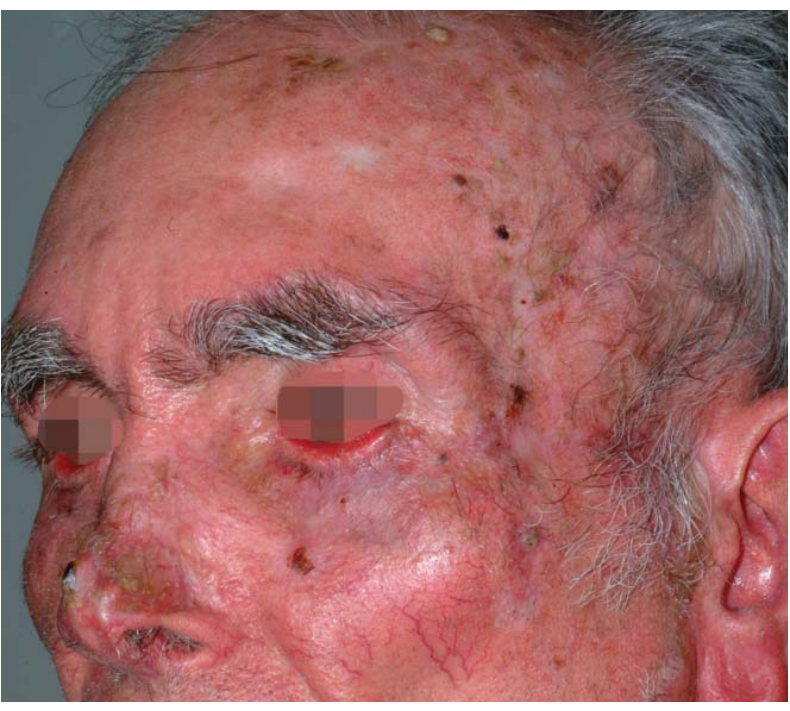

FIGURE 1: Facial skin field with multiple actinic keratoses and signs of severe photoaging and CECs

Due to the high incidence of QAs and their preferred location on exposed areas (head, neck, upper limbs), it is imperative that an effective treatment of theses lesions be performed as well as protective measures to reduce their number and prevent the development of new ones on the treated field. QAs are considered the most common pre-malignant cutaneous lesions, and some authors prefer to classify them as spinocellular carcinoma (CEC) in situ..$^{13}$ In the northern hemisphere, the prevalence of QAs varies from 11 to $25 \%$ in the population over 40 years of age. There is both the possibility of transformation to invasive CEC as well as an underlying metastatic potential in theses lesions. It is estimated that CEC is responsible for as much as $34 \%$ of death causes for skin cancer in people aged 65 to 84 years old and for $56 \%$ in patients over 85 years old. ${ }^{11}$

Although QAs may suffer voluntary regression, the risk of progression to CEC varies from $0.025 \%$ to $20 \%$ a year. ${ }^{11,12,17}$ In the course of one year, about $20 \%$ to $25 \%$ of lesions do regress. However, on the same period of time, $15 \%$ of the lesions that suffer regression emerge again. ${ }^{11}$ It is very hard and inaccurate to estimate if the regression will be permanent or temporary. Thus, diagnosis and treatment are pertinent. It was estimated that $60 \%$ of Caucasian individuals might present at least one lesion after the age of $400^{11,12}$ QAs are normally present in photoexposed areas and are multiple, resulting in areas of cancerization. Since one cannot predict which lesion will regress and which will transform to CEC, it is mandatory that all lesions be treated. More and more emphasis is placed on the treatment of the entire field, since sub clinical lesions may transform to CEC. ${ }^{1,2}$
Sub clinical lesions in a field are common and share the same histopathological characteristics of clinically visible QAs. It is estimated that sub clinical foci are 10 times more frequent than QAs inside a field. ${ }^{18,19}$ These lesions might be identified by confocal microscopy technique and also by photodiagnosis with blue light and previous application of 5-delta aminolevulinic acid (5-ALA) or methyl aminolevulinate (MAL). ${ }^{13}$

Quaedvlieg et al, performed a systematic review of retrospective studies and identified risk factors for the progression of field lesions. ${ }^{11}$ The most suggestive clinical signs of transformation from QA to CEC were: infiltration, inflammation, diameter over 1 $\mathrm{cm}$, rapid growth, bleeding, erythema and ulceration. Other important risk factors to be considered are larger hyperkeratotic lesions and lesions located on lips, nose, ears and eyelids. Male gender, aging, previous history of skin cancer, phototypes I and II, frequent solar exposure and immunosuppression were also considered relevant factors. ${ }^{12,14}$

Histologically, QAs are classified according to keratinocyte atypia, nuclear pleomorphism, hyperkeratosis, parakeratosis, dermic inflammatory infiltrate and concomitant solar elastosis. Sub clinical field lesions also present similar histopathological alterations, including foci of keratinocytes with various degrees of atypia, disorganization, loss of cellular polarity, hyper and parakeratosis, besides dermic modifications due to excessive damage secondary to UV radiation exposure, such as solar elastosis, vascular ectasia, and reduction of intact collagen fibers (Figure 2). In a similar study, conducted by our group, we observed all theses alterations in biopsies of apparently normal skin inside fields in several degrees of expression (Figure 3)..$^{20}$

Variable expressions of an extracellular matrix protein (denominated Tenascin-C - or Tn-C) were recently discovered both in QA lesions as well as in CEC. ${ }^{21}$ This is a protein normally present in neural embryonic tissue, during the several phases of skeletogenesis and vasculogenesis and also in reparation and muscle-skeletal tissues. Its function is directly linked to adhesion, migration and cellular growth, angiogenesis and regulation of the expression of MMPs. ${ }^{21}$ Its role on tumoral invasion is still uncertain, but recent studies demonstrated an increase in Tn-C expression in QAs with a higher degree of atypia and also that the intensity of reaction and its extension were larger on CECs than on QAs. Tn-C expression was particularly more intense on CEC basal cells, at the edge of tumoral invasion. This observation seems to correlate with the invasion potential of theses tumors, in which a larger expression of Tn-C may be linked to a diminished cellular adhesion favoring 


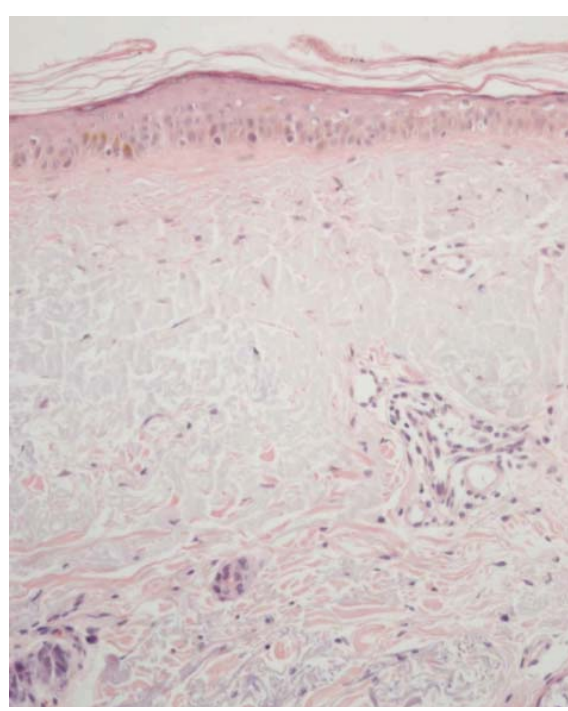

FIGURE 2:

Microphotograph $\mathrm{y}$ of skin in a field with atrophic epidermis, atypia, loss of normal keratinocyte polarization and intense degeneration of the dermic collagen with solar elastosis. Hematoxiline and Eosin 400x

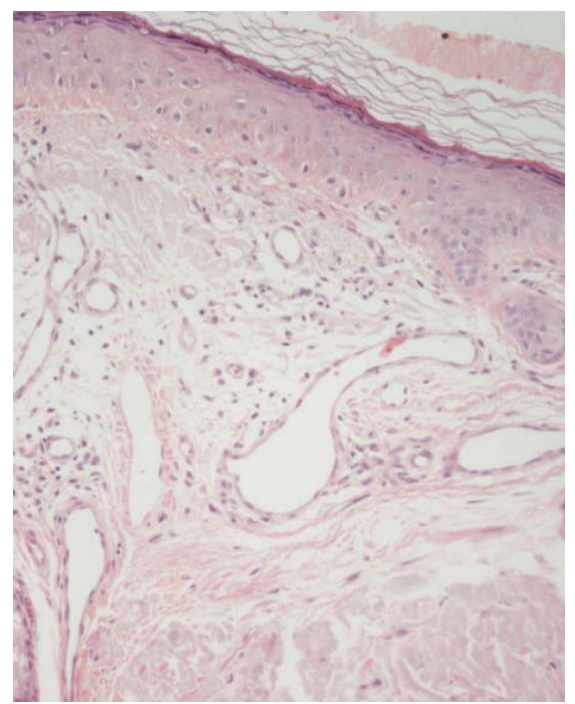

FIGURE 3:

Microphotograph $\mathrm{y}$ of skin in a field with characteristics similar to Figure 2, but with intense solar elastosis and multiple vascular ectasias in the superior $\mathrm{d}$ e $\mathrm{r} \mathrm{m}$ i $\mathrm{s}$. Hematoxiline and Eosin 400x

invasion and dissemination of the tumors. ${ }^{21}$ However, the role of this protein on field cancerization is still unknown. In a previous study performed by our group, we evaluated the expression of $\mathrm{Tn}-\mathrm{C}$ in individual submitted to multiple sessions of photodynamic therapy (TFD) and subsequent biopsies on apparently normal skin located inside the field. We observed a significant increase in the levels of Tn-C after 3 sessions of TDF on the field. Maybe this elevation was a consequence of the intense inflammatory process; once IL-4, TNF- $\alpha$, and INF- $\gamma$ are all elevated after the treatment and also that the area biopsied was not a QA clinical lesion. ${ }^{20}$

\section{THERAPEUTIC OPTIONS}

The correct diagnosis and treatment of QAs, and of the field are fundamental, once clinical and sub clinical lesions may evolve to invasive CEC. There are plenty of therapeutic options available to treat QA and to choose the most appropriated to each patient the following factors must be considered: 1- number, extension, duration, localization and clinical evolution of lesions; 2- patient's age, co-morbidities, immunosuppression, past history of skin cancer and frequency of solar exposure; 3 - cost of procedure; 4 - the physician's expertise with that technique and finally, 5- the patient's preference. ${ }^{14}$ When several lesions are present in an extensive area or when there is suspicion of sub clinical lesions, configuring field cancerization, treatment for the entire field must be considered, and not only for the isolated lesions. Patients with multiple lesions may be treated with combined methods, i.e., field treatment and destructive procedures for the lesions. Despite the chosen treatment method, the periodic follow-up of patients with field cancerization is of the utmost importance to determine the percentage of cure and identify, in an early fashion, the presence of new lesions and the possibility of transformation to CEC (Figure 4).

\section{TREATMENT OF LESIONS}

Classically, cryosurgery with liquid nitrogen is the treatment of choice in this category, even though there is not a standardization of the method. This is a simple, low-cost, quick and efficient procedure, largely used to treat isolated lesions, and that presents cure rates between $65 \%$ and $75 \% .^{14,22}$ The adverse events such as pain, blistering, scabbing and risk of depigmentation may however, turn this method undesirable for some patients. ${ }^{14,22}$ Ablative lasers, particularly $\mathrm{CO}_{2}$ and Erbium: YAG may be used to treat isolated lesions; this method however is more expensive and dependent on the existence of a highly trained professional. High fluence therapies may also result in pain and depigmentation of the treated area. Other destructive methods, applied to treat isolated lesions are curettage and electrocoagulation. Both are effective and low-cost, but require local anesthesia and have a high incidence of depigmentation..$^{14,18,19}$

\section{FIELD CANCERIZATION TREATMENT}

The therapeutic options used to treat fields are mainly those used for multiple visible and palpable QAs in contiguous skin areas, sub clinical lesions or extensive photoexposed areas that have a high likelihood to develop cutaneous non-melanocytic neoplasms. ${ }^{14,20,23}$ Patients with new or recurring field lesions are also potential candidates for this approach. Treatment of the entire field efficiently removes clinical lesions and reduces the potential risk for the appearance of new lesions and CEC. ${ }^{18,19}$

For educational purposes, field treatment can be divided in 3 groups: 1- use of topical drugs applied 


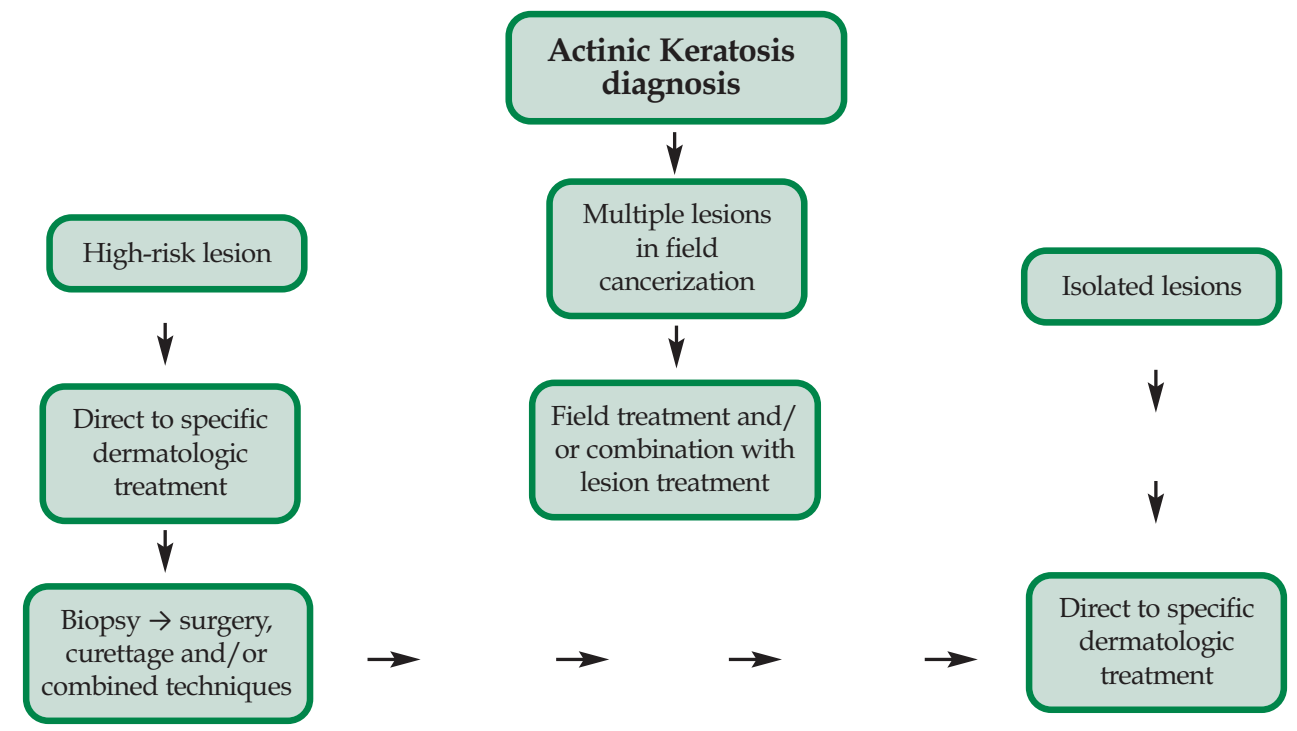

FIGURE 4: Simplified algorithm for the treatment of isolated or field QAs

Adapted source: Stockfleth $e t a l^{14}$

by the patient; photodynamic therapy (TFD) and 3resurfacing surgical procedures performed with ablative lasers, dermabrasion and chemical peelings.

On the first group are all the drugs of topical use such as 5- fluorouracil, imiquimod and diclofenac gel. The efficacy and safety are already proven in field treatment, but there are the disadvantages of a lengthy treatment, important adverse events and low adherence by the patients, increasing the likelihood of relapse or inadequate treatment. TFD is performed by the physician, has high cure rates and excellent cosmetic results after one or two sessions. However, the cost is higher and there is a painful feeling during the application. On the third group, resurfacing laser procedures are highly effective to treat fields, but they are also expensive and very much dependent on the expertise of the professional. Although effective for field treatment, post-procedure care is necessary due to the risk of infectious complications and depigmentation. Medium and deep chemical peelings and also dermabrasion are frequently used, but the patient must receive anesthesia, there may be bleeding (in the case of dermabrasion) and they may also be associated to adverse events such as depigmentation, bacterial and viral infections and higher rates of QA recurrence in the field. ${ }^{19}$

\section{5- FLUOROURACIL}

5- fluorouracil or simply 5-FU, is a chemotherapic drug of topical use that is necessary to synthesize DNA, besides interfering with the RNA function. In Brazil, this drug is available as a cream in concentra- tions of $5 \%$, although it may also be found in solutions and creams of $0.5 \%, 1 \%, 2 \%$ and $5 \% .{ }^{19}$ The 2007 consensus on 5-FU use in QAs suggested that the drug should be applied twice a day for 6 weeks, with high rates of cure (between $70 \%$ and $80 \%$ ), although relapse rates as high as $55 \%$ were also reported..$^{12,14,24-26}$ Other treatment schemes, such as intermittent application in wrists were use in order to obtain fewer adverse events, but their long term efficacy is debatable. ${ }^{25}$ The main disadvantages in using 5-FU are the length of treatment and the associated adverse events, such as itching, prolonged erythema, pain, ulceration and erosion, secondary infection and depigmentation. Sun exposure also increases the intensity of those reactions. The previous application of low-potency topical corticoids, 15 minutes before 5-FU, was tested to reduce of the inflammatory response. ${ }^{19}$ The combination of $0.5 \% 5-\mathrm{FU}$ and $10 \%$ salicylic acid seems to have greater efficacy and fewer adverse events, but more studies are necessary to prove its long term results. According to the British Association of Dermatologists Therapy Guidelines, the level of recommendation for 5FU in the treatment of field QAs is A and the quality of the evidence, based on the studies is $\mathrm{I}^{12}$ In a comparative, blind trial, with a 3 month follow-up, tretinoin and 5-Fu in combination were more effective, than isolated 5-FU to treat QAs in the dorsal area of the hands. ${ }^{12}$

\section{IMIQUIMOD}

Imiquimod is an imidazoquinoline amine, considered an unspecific, topical immunomodulator that 
acts as toll like receptor-7 (TLR-7) agonist. Its exact mechanism of action, antiviral and antitumor activities are still unknown. Although in vitro studies did not show direct evidence of antiviral effect, in vivo this drug may exhibit both antiviral and antitumor effects by inducing cytokines and intensifying cell mediated cytolysis. Imiquimod stimulates natural immune response by inducing cytokines, and acquired cellular immune response by inducing interferon-alpha, interferon-gamma, IL-2 and TNF- $\alpha$. When applied topically, this cytokine stimulation produces local inflammation. Another possible mechanism of action for Imiquimod could be through its capacity of modulating the function of Langerhans cells, increasing their migration from lymph nodes to the skin. ${ }^{27}$

This drug is available in creams with concentrations of $3.75 \%$ and $5 \%$. The lowest concentration is FDA (Food and Drug Administration) approved and has several advantages such as the possibility of application in broader areas and even shorter schemes with 2 applications a day for 6 weeks. ${ }^{14}$ Several well-conducted randomized controlled clinical trials on Imiquimod, using placebo and other controls, demonstrated rates of cure of $45 \%$ to $84 \%$ and recurrence rates of $10 \%$ in 12 months and $20 \%$ in 24 months. ${ }^{28-30}$ Treatment schemes vary from applications 2 to 3 times a week up to daily use for 16 weeks. A recent study by Stockfleth et al, compared imiquimod in a shorter 4-week scheme with the option of 4 additional weeks, which was as effective as the routine treatment of 16 continued weeks. ${ }^{31}$ Comparative studies between 5-FU (twice a day for 4 weeks) and imiquimod (2 to 3 times a week for 16 weeks) showed superior results for 5-FU initially. However, the rates of histological cure and extended cure during 12 months of follow-up were higher in the imiquimod group. ${ }^{14,18,19}$ (Figure 5).

A lengthy treatment combined to adverse events such as pain, blistering, erosion, ulceration and also systemic symptoms like fever, headache and malaise must be carefully considered, specially regarding the correct adherence of the patients with QA field lesions. In order to achieve a good adherence, the physician must explain with details all the adverse events to be expected from the chosen treatment. According to the British Association of Dermatologists Therapy Guidelines, the level of recommendation for imiquimod in the treatment of field QAs is B and the quality of the evidence, based on the studies is $I^{12}$

\section{RESIQUIMOD}

Resiquimod is also an imidazoquinoline amine immunomodulator that acts as TLR-7 and TLR-8 agonist. It induces a stronger response from dendritic myeloid cells and greater expression of IL-12 and TNF- $\alpha$ than imiquimod. In a European phase II study, four different gel concentrations were used topically, once a day, thrice a week for 4 weeks in a $25-\mathrm{cm}^{2}$ area of the face and scalp. The rates of clinical cure were $40 \%$ with $0.01 \%$ gel, $74.2 \%$ with $0.03 \%$ gel, $56.3 \%$ with $0.06 \%$ and $70.6 \%$ with $0.1 \%$ gel. Patients with residual lesions were offered a second course of treatment. The authors concluded that the efficacy was similar in all four concentrations, but $0.01 \%$ and $0.03 \%$ were better tolerated. ${ }^{32}$

\section{DICLOFENAC GEL}

This is a topical drug that inhibits the prostaglandin synthesis by inhibiting the cyclooxygenase (COX) enzyme.

There are two controlled trials that evaluated $3 \%$ diclofenac gel in hyaluronan acid $2,5 \%$ versus vehicle gel for the treatment of thin QAs in fields. On the first study patients were treated for 60 days, with applications twice a day and achieved a cure rate of $70 \%$ compared to $44 \%$ for those treated only with the vehicle. ${ }^{33}$ On the second study, patients were treated for 90 days, and $50 \%$ of those treated with diclofenac gel were cured compared to $20 \%$ in the control group. The follow-up however was very short, only 30 days, which is a flaw in the study. ${ }^{34}$ The treatment, while
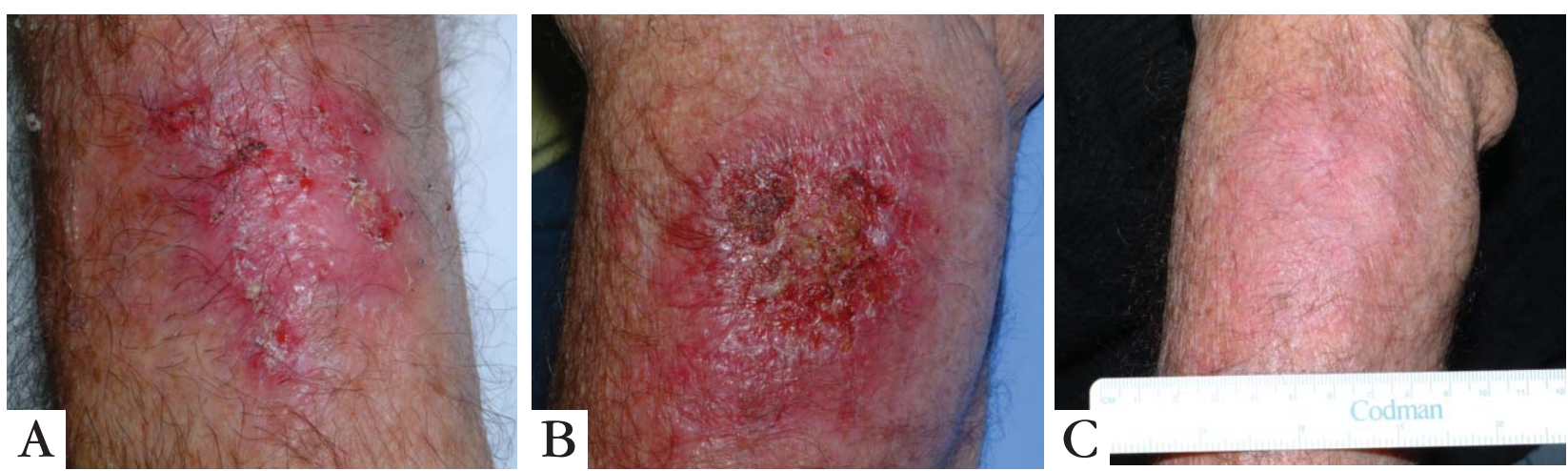

FIGURE 5: A. Bowen disease originating from an extensive QA in the forearm; B. the same lesion after 15 days of topical treatment with 5\% imiquimod; C. 2 months after completion of treatment, with lesion cured and an excellent esthetic result 
well tolerated and with less adverse events than imiquimod and 5-FU, requires total adhesion from the patient, because it is lengthier than the other topical treatments. ${ }^{14,19}$ According to the British Association of Dermatologists Therapy Guidelines, the level of recommendation for diclofenac gel in the treatment of field QAs is B and the quality of the evidence, based on the studies is $\mathrm{I}^{12}$

\section{TRETINOIN}

The topical use of tretinoin in vastly marketed as a treatment of cutaneous aging signs. Its use on field cancerization is still controversial. Bollag and $\mathrm{Ott}$ achieve complete response of QAs in $55 \%$ of patients treated with tretinoin $0.3 \%$ and $35 \%$ in the group that received the concentration of $0.1 \% \cdot{ }^{12}$ In another study, there was a $47 \%$ reduction on lesions after 15 months of treatment with a concentration of $0.05 \%$, applied one to twice a day. ${ }^{12,18}$ The level of recommendation for tretinoin in the treatment of field QAs is B and the quality of the evidence, based on the studies is $\mathrm{I}^{12}$ Therefore, this is a drug directed more to cutaneous photoaging treatment than to field cancerization.

\section{PHOTOPROTECTION}

The daily use of photoprotectors combines the effects of the emollient components to an active antisolar protection. Their daily applications, in schemes of 1 to 2 times a day, was superior when compared to the isolated vehicle, regarding total number of QAs and the appearance of new lesions. ${ }^{12,14,35}$ According to the British Association of Dermatologists Therapy Guidelines, the level of recommendation for photoprotectors in the treatment of field QAs is A and the quality of the evidence, based on the studies is $\mathrm{I} .^{12}$

\section{INGENOL MEBUTATE}

Although long used to treat warts and skin cancer, even without a scientific base, this caustic substance is new to the treatment of field cancerization. ${ }^{36}$ This is a diterpene ester, derived from the plant Euphorbia peplus and approved for the treatment of QAs. The mechanism of action is still controversial, but there seems to be two basic steps to destroy the tumor: 1- induction of cell death by the loss of the plasmatic and mitochondrial membrane's integrity and 2- production of inflammatory cytokines and induction of an expressive neutrophilic and lymphocytic inflammatory infiltrate. ${ }^{36,37}$

A recent multicentric, double-blinded, randomized trial included patients with QAs in face, scalp, torso and limbs. They were treated with ingenol mebutate $0.015 \%$ for 3 consecutive days, in lesions of face and scalp in a $25-\mathrm{cm}^{2}$ area. The group with lesions of torso and limbs used the drug in a concentration of
$0.05 \%$ for 2 consecutive days also in a $25-\mathrm{cm}^{2}$ area. The adverse events peaked on day 4 and diminished on day 8 , returning to the basal level on day 29 for the group treated in the face and scalp. For the group with torso and limb lesions, the adverse events peaked between days 3 and 8 and returned to basal levels on day 29. The mean reduction on the number of lesions was $83 \%$ and $75 \%$ for face/scalp and torso/limbs groups respectively. Adverse events (erythema, edema, blistering, itching and erosions) varied from mild to severe according to recent studies. Cozzi et al, observed that ingenol mebutate not only reduced in $70 \%$ the QAs lesions in mice irradiated with UV-B, but also reduced the TP-53 mutate expressed in the field, which might indicate a chemopreventive effect. ${ }^{38}$ The greatest potential of this new drug, besides its effica$\mathrm{cy}$, resides on the convenience of the posology and the high rate of adherence, since the treatment application scheme is of 2 or 3 days. There are still no long-term efficacy studies on this subject published.

\section{PHOTODYNAMIC THERAPY}

TFD is a therapeutic option particularly effective to treat field cancerization QAs and nonmelanocytic skin cancers. ${ }^{23}$ The procedure requires the application of a 5-ALA or MAL precursor agent that will be converted to the photosensitizing molecule PPIX (protoporphyrin IX) inside the neoplastic or preneoplastic cell, rendering the lesion susceptible to radiation with visible wavelengths in blue or red spectrums. ${ }^{23,29}$ This process, known as photodynamic activation induces the formation of reactive $\mathrm{O}_{2}$ radicals, mainly ${ }^{1} \mathrm{O}_{2}$, with posterior necrosis of the dysplastic cells that form QAs. ${ }^{20,23,39-42}$ Cure rates are as high a $75 \%$ to $92 \%$ after one or two sessions of TFD. The final cosmetic effect is considered excellent in all studies. ${ }^{41-48}$ (Figure 6) The major obstacle resides in how to manage the pain, as treating extensive areas of cancerization fields will promote the formation of large amounts of PPIX and consequently, induce heavy photodynamic activation, with subsequent pain during the treatment. ${ }^{40}$ The correct protocol with 5-ALA must be performed with blue light after a period of incubation of 14-18 hours. With MAL, the time of incubation is 3 hours, followed by a session with red light. ${ }^{23,29}$ This treatment is particularly effective for QAs grades II and I located on face and scalp; while results on limb lesions are inferiors to the ones obtained on the face. ${ }^{39}$ Braathen et al, recently demonstrated that, 1 hour incubation with MAL may be enough and as effective as 3 hours in the treatment of thin QAs of face and scalp. ${ }^{41}$ One the same line, a shorter period of incubation for 5-ALA is already used in the clinical practice. Recently, Kleinpenning et al evaluated the efficacy of TFD with MAL on QAs 

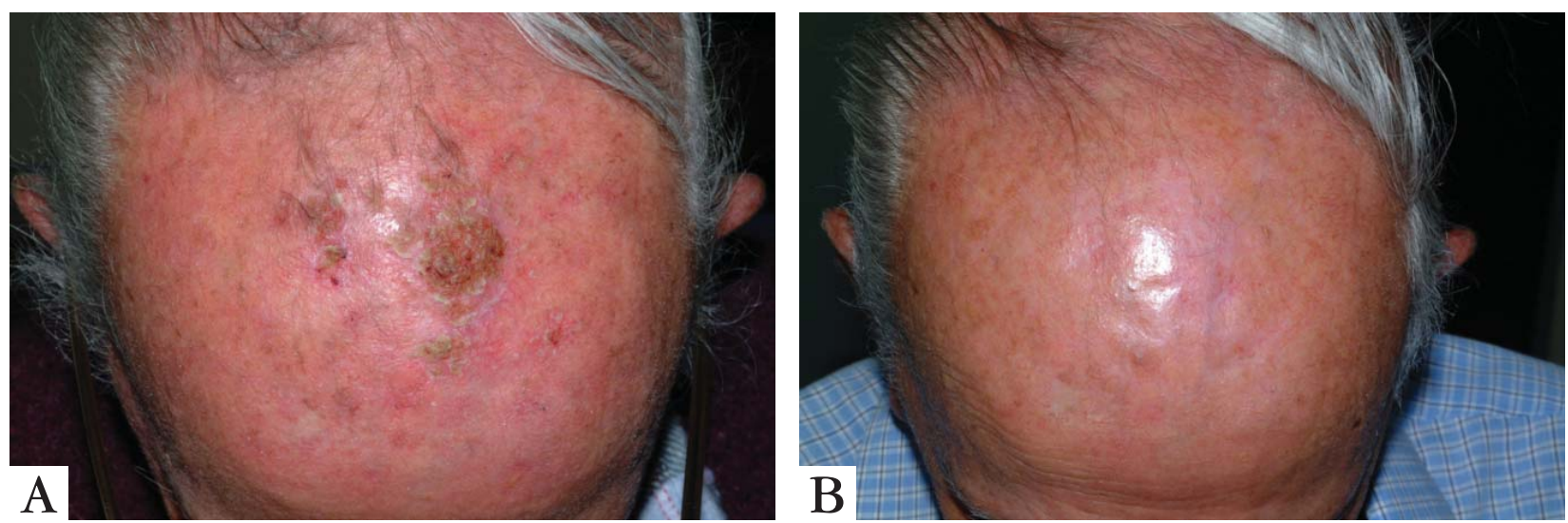

FIGURE 6: A. Extensive field area in the frontal-parietal region with multiple QAs and in situ CEC in the center; B. The same patient 3 months after 2 sessions with TFD and topical MAL, with resolution of the lesions and excellent esthetic result

lesions in patients with moderate to severe grades of photodamage in their face and scalp. In this study, 14 patients with 223 QAs on face and scalp were submitted to two sessions of TFD and MAL with an interval of 3 months between sessions. Patients were evaluated three months after the second session and the authors found an expressive improvement in the degree of global facial photodamage. The overall rate cure for lesions after one session was $54,7 \%$ and after two sessions it was $61.9 \%$. Complete resolution of QAs was only observed in patients with moderate photodamage, and partial resolution was observed in those with severe photodamage. None of the patients with complete response had relapses or the emergence of new lesions during the study and in the 6month follow-up. The authors concluded that a larger number of sessions might be necessary to effectively treat patients with severe photodamage and QAs. ${ }^{42}$ Bagazgoitia et al demonstrated, in 2001, that TFD with mal and red LED reduced the histopathological alterations in the fields and also the expression of oncogenic markers in the photoaged skin. ${ }^{43}$ In 2012 our team demonstrated, as well, the potential effect in reducing TP-53 expression and reverse cellular atypia on the skin. ${ }^{20}$ Apalla et al. studied the potential preventive effect of TFD with 5-ALA in the appearance of new QAs in fields on immunocompetent patients. ${ }^{44}$ In this study, patients with multiple QAs on face and scalp were randomized to receive TFD plus 5-ALA or placebo, with one year of follow-up. After only one session, the number of new lesions in areas treated with placebo was more than double the areas treated with TFD plus 5-ALA, in the end of the 12-month follow-up. Likewise, $64 \%$ of the areas treated with 5ALA plus TFD did not show new lesions. Up to the sixth month of follow-up there was a marked difference in the emergence of new lesions when the two groups were compared. After this period, the rate of new lesions appearance on the area treated with 5ALA gradually increased. These data suggest that TFD may have preventive value to avoid the appearance of new QA lesions in the fields and also that repeated interventions with TFD in patients with severe photodamage might help prevent nonmelanocytic skin cancers in field cancerization. ${ }^{44}$ However, which would be the best treatment scheme for the latter is already unknown.

Another option, within the classic TFD is the modality known as daylight PDT. This is the activation of PPIX by sunlight instead of by artificial red or blue lights. Recent studies by Wiegell et al demonstrated similar levels of efficacy with less pain during the treatment when compared to conventional TFD. ${ }^{45}$ Recent studies in our group showed that, results are similar and the level of pain is greatly reduced comparing to classic TFD. However, we are still waiting for the dosimetry of red light emitted by solar radiation, in our midst, to adjust for the right amount of time and solar exposure.

In 2012, the European guidelines for topical photodynamic therapy suggested that the level of recommendation for TFD to treat field cancerization is B and the quality of evidence $\mathrm{I}^{46}$

\section{FIELD CANCERIZATION TREATMENT IN HIGH RISK GROUPS}

Treatment of field QAs in high-risk patients must be carefully evaluated. High-risk lesions must always be biopsied. QAs located on lips, ears and eyelids have greater potential for malignant transformation. ${ }^{14}$ Surgical resection or curettage followed by electrocoagulation may be considered good options for localized lesions. Topical treatment may be administered in areas that would be difficult to treat with cryosurgery and/or surgery. ${ }^{14}$ Patients submitted to transplants are considered of higher risk for the devel- 
opment of skin CEC. It is estimated that they have 10 times more chance of developing basocellular carcinoma (CBC) and 40 to 150 more chance to evolve with $\mathrm{CEC}$ as well as a higher risk of progression from QAs to CEC. ${ }^{39}$ This group of patients also presents with multiple lesions and more aggressive, more metastatic CEC when compared to the immunocompetent population. It should be noticed that patients with history of non-melanocytic skin cancer previous to the transplant have higher chances of developing new tumors after the procedure. Patients with heart transplants, for their age and immunosuppressant regimen are the most susceptible to CEC. ${ }^{14,39}$

There are few data in medical literature regarding treatment of these high-risk patients. Wulf et al showed that in patients with kidney transplants, the time to develop tumor was slightly bigger in the group treated with MAL-TFD than in the control group. ${ }^{47}$ Wennberg et al evaluated the effect of MALTFD in another randomized trial. The authors observed a distinct reduction in the number of new QA lesion in the area treated with TFD compared to the area treated with cryosurgery after 3 months. The results were maintained for 15 months of follow-up, but at 27 months there was no difference between the groups. This observation suggests that multiple and repeated sessions of TFD in extensive areas might prevent the appearance of field QA in transplanted patients. ${ }^{48}$ Wiley et al observed a reduction in the incidence of CEC in transplanted patients after multiple sessions with TFD and a follow-up of 24 months. ${ }^{49}$ Ulrich et al, in a multicentric randomized trial, evalu- ated the effect of imiquimod thrice a week, for 16 weeks, in an area of $100 \mathrm{~cm}^{2}$ in transplanted patients. Efficacy was superior in the group treated with imiquimod, without adverse events related to the transplant, showing that this is a safe and effective option in high-risk patients with field cancerization. ${ }^{50}$ Also of notice, the results obtained in the reduction of QAs were similar to the observed in the immunocompetent population in this study. ${ }^{50}$

\section{FINAL COMMENTS}

Given the facts, it is necessary to consider the cutaneous field cancerization as one photoexposed area that is highly damaged by UV radiation and that contains clinical and sub clinical lesions. Much has been done; up-to present, to treat the visible lesions. However, even with the correct treatment, these patients had a high rate of relapse, as well as the emergence of new lesions in the field. These patients must be considered with the utmost care, for they present with an absolutely chronic condition with not only the higher risk to develop invasive CEC, but also new and multiple QA lesion. Therefore, they must be frequently monitored and submitted to the treatment of the entire field, in order to approach the visible and sub clinical lesions. In this sense, a possibly preventive effect will be promoted, to avoid the appearance of non-melanocytic skin cancers. It is noteworthy that, there are several therapeutic options available and dermatologists must choose the technique that they are most familiar with and also the one that is based on well-conducted clinical trials. $]$

\section{REFERENCES}

1. Slaughter DP, Southwick HW, Smejkal W. Field cancerization in oral stratified squamous epithelium. Cancer. 1953;6:963-8.

2. Braakhuis BJ, Tabor MP, Kummer JA, Leemans CR, Brakenhoff RH. A genetic explanation of Slaughter's concept of field cancerization: evidence and clinical implications. Cancer Res. 2003;63:1727-30.

3. Brennan JA, Mao L, Hruban RH, Boyle JO, Eby YJ, Koch WM, et al. Molecular assessment of histopathological staging in squamous cell carcinoma of the head and neck. N Eng J Med. 1995;332:429-35.

4. Califano J, Leong PL, Koch WM, Eisenberger CF, Sidransky D, Westra WH. Second esophageal tumors in patients with head and neck squamous cell carcinoma: an assessment of clonal relationships. Clin Cancer Res. 1999:5:1862-7.

5. Tabor MP, van Houten VM, Kummer JA, Vosjan MJ, Vlasblom R, Snow GB, et al. Discordance of genetic alterations between primary head and neck tumors and corresponding metastases associated with mutational status of the TP53 gene. Genes Chromosomes Cancer. 2002;33:168-77.

6. Jonason AS, Kunala S, Price GJ, Restifo RJ, Spinelli HM, Persing JA, et al Frequent clones of P53-mutated keratinocytes in normal human skin. Proc Natl Acad Sci U S A. 1996; 93:14025-29

7. Berg RJ, van Kranen HJ, Rebel HG, de Vries A, van Vloten WA, Van Kreijl CF, et al. Early p-53 mutations in mouse skin carcinogenesis by UV-B radiation: immunohistochemical detection of mutant p-53 protein clusters of pre-neoplastic epidermal cells. Proc Natl Acad Sci U S A. 1996:93:274-8.

8. Olivier M, Hollstein M, Hainault P. TP53 mutations in human cancers: origins, consequences and clinical use. Cold Spring Harb Perspect Biol. 2010; 2:a001008.

9. Brennan JA, Boyle JO, Koch WM, Goodman SN, Hruban RH, Eby YJ, et al. Association between cigarette smoking and mutation of the p-53 gene in squamous cell carcinoma of the head and neck. N Eng J Med. 1995; 332.712-7.

10. Waridel F, Estreicher A, Bron L, Flaman JM, Fontolliet C, Monnier P, et al. Field cancerization and polyclonal p53 mutation in the upper acrodigestive tract. Oncogene. 1997;14:163-9.

11. Quaedvlieg PJ, Tirsi E, Thissen MR, Krekels GA. Actinic keratosis: how to differentiate the good from the bad ones? Eur J Dermatol. 2006:16:335-9.

12. de Berker D, McGregor JM, Hughes BR; British Association of Dermatologists Therapy Guidelines and Audit Subcommittee. Guidelines for the management of actinic keratoses. Br J Dermatol. 2007;156:222-30.

13. Ulrich M, Maltusch A, Röwert-Huber J, González S, Sterry W, Stockfleth E, et al. Actinic keratoses: non-invasive diagnosis for field cancerization. $\mathrm{Br} J$ Dermatol. 2007; 156:13-7.

14. Stockfleth E, Ferrandiz C, Grob JJ, Leigh I, Pehamberger H, Kerl H, et al. Development of a treatment algorithm for actinic keratoses: a European Consensus. Eur J Dermatol. 2008;18:651-9.

15. Kohl E, Torezan LA, Landthaler M, Szeimies RM. Aesthetic effects of topical photodynamic therapy. J Eur Acad Dermatol Venereol. 2010;24:1261-9.

16. Röwert-Huber J, Patel MJ, Forschner T, Ulrich C, Eberle J, Kerl H, et al. Actinic keratosis is an early in situ squamous cell carcinoma: a proposal for reclassification. Br J Dermatol. 2007;156:8-12.

17. Glogau RG. The risk of progression to invasive disease. J Am Acad Dermatol. 2000;42:S23-4. 
18. Berman B, Cohen DE, Amini S. What is the role of field-directed therapy in the treatment of actinic keratosis? Part 1: overview and investigational topical agents. Cutis. 2012;89:241-50.

19. Berman B, Cohen DE, Amini S. What is the role of field-directed therapy in the treatment of actinic keratosis? Part 2: commonly used field-directed and lesion directed therapies. Cutis. 2012;89:294-301.

20. Szeimies RM, Torezan L, Niwa A, Valente N, Unger P, Kohl E, et al. Clinical, histopathological and immunohistochemical assessment of human skin field cancerization before and after photodynamic therapy. Br J Dermatol. 2012;167:150-9.

21. Dang C, Gottsschilling M, Roewert J, Forshner T, Stockfleth E, Nindl I. Tenascin-C patterns and splice variants in actinic keratosis and cutaneous squamous cell carcinoma. Br J Dermatol. 2006;155:763-70.

22. Szeimies RM, Karrer S, Radakovic-Fijan S, Tanew A, Calzavara-Pinton PG, Zane C, et al. Photodynamic therapy using topical methyl 5-aminolevulinate compared with cryotherapy for actinic keratosis: a prospective, randomized study. J Am Acad Dermatol. 2002; 47:258-62.

23. Torezan L, Niwa AB, Neto CF. Photodynamic therapy in dermatology: basic principles. An Bras Dermatol. 2009;84:445-59.

24. Kurwa HA, Yong-Gee SA, Seed PT, Markey AC, Barlow RJ. A randomized paired comparison of PDT and topical 5-FU in the treatment of actinic keratosis. J Am Acad Dermatol. 1999;41:414-8.

25. Epstein E. Does intermittent pulse topical 5-FU therapy allow destruction of actinic keratosis without significant inflammation? J Am Acad Dermatol. 1998;38:77-80.

26. Gupta AK. The management of actinic keratoses in the United States with topical fluorouracil: a pharmacoeconomic evaluation. Cutis. 2002;70:30-6.

27. Festa-Neto C. Imiquimod $5 \%$ cream in the treatment of superficial and nodular basal cell carcinomas: study of 10 cases. An Bras Dermatol. 2002;77:693-8.

28. Korman N, Moy R, Ling M, Matheson R, Smith S, McKane S, et. Dosing with 5\% imiquimod cream 3 times per week for the treatment of actinic keratosis: results of two phase 3, randomized, double-blind, parallel-group, vehicle-controlled trials. Arch Dermatol. 2005;141:467-73.

29. Szeimies RM, Gerritsen MJ, Gupta G, Ortonne JP, Serresi S, Bichel J, et al. Imiquimod 5\% cream for the treatment of actinic keratosis: results from a phase III, randomized, double-blind, vehicle-controlled clinical trial with histology. J Am Acad Dermatol. 2004:51:547-55.

30. Lebwohl M, Dinehart S, Whiting D, Lee PK, Tawfik N, Jorizzo J, et al. Imiquimod $5 \%$ cream for the treatment of actinic keratosis: results from two phase III, randomized, double-blind, parallel group, vehicle controlled trials. J Am Acad Dermatol. 2004; 50:714-21.

31. Stockfleth E, Sterry W, Carey-Yard M, Bichel J. Multicenter, open-label study using imiquimod $5 \%$ cream in one or two 4-week courses of treatment for multiple actinic keratosis on the head. Br J Dermatol. 2007;157:41-6.

32. Szeimies RM, Bichel J, Ortonne JP, Stockfleth E, Lee J, Meng TC. A phase II doseranging study of topical resiquimod to treat actinic keratosis. BrJ Dermatol. 2008;159:205-10.

33. Rivers JK, Arlette J, Shear N. Topical treatment of actinic keratosis with $3 \%$ diclofenac in 2,5\% hyaluronan gel. Br J Dermatol. 2002;146:94-100.

34. Rivers JK, Arlette J, Shear N, Guenther L, Carey W, Poulin Y. Topical 3\% diclofenac in 2,5\% hyaluronan gel in the treatment of actinic keratosis. Int J Dermatol 2001; 40: 709-13.

35. Darlington S, Williams G, Neale R, Frost C, Green A. A randomized controlled trial to assess sunscreen application and beta-carotene supplementation in the prevention of solar keratoses. Arch Dermatol. 2003;139:451-5.

36. Rosen RH, Gupta AK, Tyring ST. Dual mechanism of action of ingenol mebutate gel for topical treatment of actinic keratoses: rapid lesion necrosis followed by lesionespecific immune response. J Am Acad Dermatol. 2012;66:486-93.

37. Lebwohl M, Swanson N, Anderson LL, Melgaard A, Xu Z, Berman B. Ingenol mebutate for actinic keratosis. N Engl J Med. 2012;366:1010-9.

38. Cozzi SJ, Ogbourne SM, James C, Rebel HG, de Gruijl FR, Ferguson B, et al. Ingenol mebutate field-directed treatment of UVB-damaged skin reduces lesion formation and removes mutant p53 patches. J Invest Dermatol. 2012;132:1263-71.

39. Braathen LR, Szeimies RM, Basset-Seguin N, Bissonnette R, Foley P, Pariser D, et al. Guidelines on the use of photodynamic therapy for non melanoma skin cancer: an international consensus. J Am Acad Dermatol. 2007;56:125-43.

40. Chaves YN, Torezan LA, Niwa AB, Sanches Junior JA, Festa Neto C. Pain in photodynamic therapy: mechanism of action and management strategies. An Bras Dermatol. 2012;87:521-6.
41. Braathen LR, Paredes BE, Saksela O, Fritsch C, Gardlo K, Morken T, et al. Short incubation with methylaminolevulinate for photodynamic therapy of actinic keratosis. J Eur Acad Dermatol Venereol. 2008;23:550-5.

42. Kleinpenning MM, Van de Kerkhof PC, Gerritson RM. The clinical efficacy of topical MAL-PDT in moderate to severe actinic keratoses of the face and scalp. $J$ Dermatolog Treat. 2010;21:252-7.

43. Bagazgoitia L, Cuevas Santos J, Juarranz A, Jaén P. Photodynamic therapy reduces the histological features of actinic damage and the expression of early oncogenic markers. Br J Dermatol. 2011;165:144-51.

44. Apalla Z, Sotiriou E, Chovarda E, Lefaki I, Devliotou-Panagiotidou D, Ioannides D. Skin câncer: preventive photodynamic therapy in patients with face and scalp cancerization. A randomized placebo-controlled study. Br J Dermatol. 2010;162:171-5.

45. Wiegell SR, Fabricius S, Stender IM, Berne B, Kroon S, Andersen BL, et al. A randomized multicentre study of directed daylight exposure times of $1 \frac{1}{2}$ vs $2 \frac{1}{2}$ hs daylight- mediated PDT with methyl aminolevulinate in patients with multiple thin actinic keratoses of the face and scalp. Br J Dermatol. 2011;164:1083-90.

46. Braathen LR, Morton CA, Basset-Seguin N, Bissonnette R, Gerritsen MJ, Gilaberte $\mathrm{Y}$, et al. Photodynamic therapy for skin field cancerization: an international consensus. International Society for Photodynamic Therapy in Dermatology..J Eur Acad Dermatol Venereol. 2012;26:1063-6.

47. Wulf HC, Pavel S, Stender I, Bakker-Wensveen CA. Topical photodynamic therapy for prevention of new skin lesions in renal transplant recipients. Acta Derm Venereol. 2006;86:25-8.

48. Wennberg AM, Stenquist B, Stockfleth E, Keohane S, Lear JT, Jemec G, et al. Photodynamic therapy with methyl aminolevulinate for prevention of new skin lesions in transplant recipients: a randomized study. Transplantation. 2008;86:423-9.

49. Wiley A, Mehta S, Lee PK. Reduction in the incidence of squamous cell carcinoma in solid organ transplant recipients treated with cyclic PDT. Dermatol Surg. 2010;36:652-8.

50. Ulrich C, Bichel J, Euvrard S, Guidi B, Proby CM, van de Kerkhof PC, et al. Topical immunomodulation under systemic immunosuppression: results of a multicentre, randomized, placebo-controlled safety and efficacy study of imiquimod $5 \%$ cream for the treatment of actinic keratoses in kidney, heart, and liver transplant patients. Br J Dermatol. 2007;157:25-31.

\author{
MAILING ADDRESS: \\ Luís Antônio Ribeiro Torezan \\ Rua Enéas de Carvalho Aguiar, 255 - Cerqueira César \\ 05403-000 - São Paulo - SP \\ Brazil \\ E-mail: torezanluis@uol.com.br
}

How to cite this article: Torezan LAR, Festa-Neto C. Cutaneous field cancerization: clinical, histopathological and therapeutic aspects. An Bras Dermatol. 2013;88(5):775-86. 